\title{
Cats in Animal Shelters: Exploring the Common Perception that Black Cats Take Longer to Adopt
}

\author{
Lori R. Kogan ${ }^{*}$ Regina Schoenfeld-Tacher and Peter W. Hellyer
}

Department of Clinical Sciences, Colorado State University, Campus Delivery 1601, Fort Collins, CO 80523, USA

\begin{abstract}
Secondary analysis of pre-existing data from two Colorado animal shelters was conducted to assess the impact of shelter cats' coat color on time required for adoption. One shelter included adult cats and kittens, the second shelter included kittens only. Results indicated that black cats, regardless of age or sex, require the longest time to adopt. They are followed by primarily black cats with other colors. Other color cats take less time to adopt than either black cats or primary black cats with other colors. This additional time in shelters negatively impacts the health and therefore, the welfare, of black shelter cats. Factual, rather than anecdotal knowledge about black cat adoption rates may allow shelters to direct additional resources into strategies designed to increase black cat adoption rates and decrease time black cats spend in shelters.
\end{abstract}

Keywords: Cat, adoption, coat color, Colorado animal, UTI, UTRD.

\section{INTRODUCTION}

Within the last several decades, animal shelters have made significant progress towards the reduction of euthanized dogs and cats. Despite the significant efforts of these animal welfare entities, the number of euthanized dogs and cats in the US is still over 4 million, or $3 \%$, of all US dogs and cats [1]. While approximately $25 \%$ of shelter dogs are adopted and $15 \%$ are reunited with their owners, over $56 \%$ are euthanatized. Unfortunately, the most prevalent outcome for cats is euthanasia. Even though $24 \%$ of cats that enter animal shelters are successfully adopted, only $2 \%$ are reunited with their owners, and $71 \%$ are euthanatized [2].

Depending on the type of shelter and available resources, cats can reside in shelters for just a few days or stay indefinitely. Unfortunately, most shelter environments are less than ideal for cats. Although acute stress is concerning, ongoing or chronic stress can be especially problematic. Animals under stress suffer from a suppression of the immune system. Stress can place cats at increased risk for newly acquired or reactivated infectious disease and in particular, feline herpes virus, a primary cause of URTD [3, 4]. URTDs are a major cause of morbidity and mortality for cats in US animal shelters $[5,6]$.

Kittens with URTD, for example, are twice as likely to be euthanized when compared to healthy kittens [5]. URTD, for adult and juvenile cats alike, poses a risk of infection for other shelter cats, increases the difficulty of managing and separating infected cats, and decreases the likelihood of adoption [4]. The development of URTD after adoption is another major concern, impacting shelters as well as veterinarians and new owners and can often result in the

*Address correspondence to this author at the Department of Clinical Sciences, Colorado State University, Campus Delivery 1601, Fort Collins, CO 80523, USA; Tel: (970) 491-7984; Fax: (970) 491-1069;

E-mail: lori.kogan@colostate.edu return of cats to the shelter. Given its serious negative impact on several levels, it is perhaps unsurprising that URTD is the leading medical cause of feline death in shelters, and as a result, the leading cause of death of young, adoptable, cats in the United States [7].

The length of time a cat is housed in a shelter appears to directly impact its risk of acquiring URTD. Dinnage (2009) found that the probability of a cat developing URTD increases from approximately 5\% after the first 2 days in a shelter to $21 \%$ after 1 week and over $80 \%$ after 2 weeks [7]. Edinboro (1999) estimated a 5\% increase in risk for URTD for each day in the shelter, even after adjusting for age, breed, source, and vaccination status [8]. Therefore, after 7 days in a shelter, cats have a $35 \%$ estimated cumulative probability of developing URTD. Pederson (2004) [9] found that the prevalence of herpesvirus shedding in cats upon shelter entry was approximately $4 \%$, but increased to $51.7 \%$ after seven days in the shelter. Tanaka (2012) [10] reported the mean time for shelter cats to develop URI is 8.3 days. These numbers are consistent with a previous study that reported the mean number of days to develop URI is 9 days, with most cats developing URI between 5 and 14 days after entering the shelter $[4,11]$.

Clearly, the less time a cat spends in shelter, the better chances it has to remain healthy and make a successful transition to a new adoptive home. Factors that influence cat adoption decisions, therefore, are important topics to more fully understand. Although several factors that might impact adoption decisions have been assessed, an area that has received minimal attention is the impact of coat color on cat adoption rates.

Factors that might impact adoption decisions have received increased attention in recent years. Variables including activity level, playfulness, personality, and cage enrichments all have been found to impact a cat's adoptability level [12-14]. Lepper (2002) found that age, sex 
and coat color all impact a cat's likelihood of being adopted [15]. They found that younger and sexually altered female cats were most likely to be adopted. When they examined coat color, they found that white, color point, and gray cats were most likely to be adopted while brown and black cats were less likely to be adopted.

Yet, in a study on dogs conducted by Wells and Hepper [16], the impact of coat color on adoption rates was not found to be significant. These authors indicated that although black and tan dogs were least likely to be adopted, coat color was not a primary aspect in the adoption decision. Similar findings were also reported by Fantuzzi et al. [14] who found that the number of times a cat was viewed in person as well as duration of these viewings was not impacted by coat color, sex, or age. Given the importance of better understanding the factors that impact cat adoption, and the lack of consistent findings regarding coat color and its impact on cat adoption, this paper explores the impact of coat color, and specifically black coat color, on the time required for adoption of shelter cats.

\section{MATERIALS AND METHODOLOGY}

The subjects for this retrospective cohort study were cats offered for adoption in two Colorado animal shelters. Cats adopted from LHS (Fort Collins, Colorado) between $5 / 29 / 2002$ to $10 / 28 / 2011$ and the DFL (Denver, Colorado) between $5 / 7 / 92$ to $12 / 5 / 2010$ were analyzed.

LHS is Northern Colorado's only open-door animal care facility. In 2010, they received 4,196 cats and 3,946 dogs. Based on the 2010 census, Larimer county has a total population of 299,630 . The adoption process at LHS includes the use of ASPCA's Meet Your Match Program, including the "Canine-ality" and "Feline-ality" assessments and volunteers who work with potential adopters to find the best owner/animal match. After completing the assessment, potential adopters can view the adoptable animals, and after selecting one of interest, spend time getting acquainted in a visitation room. LHS encourages people to bring other animals that reside in the home, as well as any other family members, to the shelter to visit with the animal before adoption. Adoption prices range from $\$ 25$ to $\$ 125$ for cats and kittens, and $\$ 50$ to $\$ 500$ for dogs and puppies [17].

The DFL is the largest open-door animal shelter in the Rocky Mountain region [18]. The adoption process at DFL utilizes interactive Find-a-Friend stations to help people select an appropriate pet. After they obtain this information, they can view the adoptable animals and make a potential selection. The next step involves meeting with an adoption counselor who helps facilitate appropriate pet/owner matches. Adopters are encouraged to bring all family members and other animals residing in the house to the shelter to meet the potential adoptee before taking the animal home. Adoption fees for cats are $\$ 120$ for kittens under five months old, \$95 for kittens six months to one year, and \$75 for cats over one year of age. Adoption fees for puppies under five months are $\$ 250, \$ 175$ for puppies six months to one year, and $\$ 125$ for dogs over one year. In 2010 , they received $11,277 \mathrm{dogs}$ and 11,477 cats [19]. The Denver area is a large metropolitan area of approximately 600,158 people.
Each subject (cat) in this study was identified by a unique number and accompanied by descriptive information. For the purpose of this study, the data analyzed included: coat color (divided into three groups: black only, primarily black with other color(s), and other colors). These basic three groups were selected for two primary reasons. The first reason is the exploratory nature of the study. Additionally, discussion with participating shelter staff led to the conclusion that additional coat color categories would create increased potential for inconsistent, unreliable data due to the inability to consistency code coat colors. Additional variables included in the study include sex (neutered and spayed), and age (classified as kitten - less than 1 year of age, and adult at least 1 year of age). LHS provided data on kittens and adult cats while DFL provided data on kittens only (due to their limitations in data collection at the time of the study). The dependent variable analyzed was the number of days required for adoption (time between when a cat was made available for adoption and actually adopted). Statistical analysis was conducted with SPSS (version 20). Statistical significance was accepted at $\mathrm{p}<.05$.

\section{RESULTS}

\section{DFL}

The total number of cats analyzed from DFL was 13,638. Because the number of unaltered cats was relatively small, the analyzed sample was restricted to spayed $(6585,48.3 \%)$ or neutered $(7053,51.7 \%)$ cats. Eliminated from analysis were 175 intact females, 196 intact males, and 3 unknown status cats. All cats were under one year of age. Due to technological issues within DFL, data from adult cats could not be analyzed. The average age of adoption for these kittens was 89.63 days $(S D=36.41)$ with a median of 76.25. The average time lapse between the date a cat was placed up for adoption and the day it was adopted was 24.26 days (SD $=22.7$ ), with a median time of 16 days. The cats were divided into three groups based on coat color. There were $2062(15.1 \%)$ black only cats, $1910(14.0 \%)$ black primary with other color(s) cats, and 9666 (70.9\%) other colors.

\section{LHS}

A total of 15,577 cats were analyzed from LHS. Because our sample included only a small number of intact females (63), intact males (23) and unknown status cats (5), these animals were eliminated from analysis. The analyzed sample contained $7840(50.3 \%)$ spayed and 7737 (49.7\%) neutered cats. For all cats (adults and kittens), the average age of adoption was 519.43 days $(\mathrm{SD}=663.24)$ with a median of 187. The average time required for adoption (time between when a cat was made available for adoption and actually adopted) was 17.70 days $(S D=20.1)$ with a median time of 11 days.

Cases with no recorded or unknown age were excluded $(n=128)$. The average age of kittens at adoption $(n=9071)$ was 125.96 days $(\mathrm{SD}=66.99)$ with a median of 102 days. The average time required for adoption was 14.81 days (SD $=19.06$ ) with a median time of 8 days.

The average age of adoption for adult cats $(n=6378)$ was 1079.04 days $(S D=725.11)$ with a median of 773 days. The average time between when a cat was placed up for adoption 
and actually adopted was 21.63 days $(\mathrm{SD}=22.65)$ with a median time of 15 days.

The cats were divided into three groups based on coat color $(\mathrm{n}=15,577)$. There were $1992(12.9 \%)$ cats with only black as a coat color, 1891 (12.2\%) were primarily black with other color(s), and $11566(74.9 \%)$ cats had other coat colors (e.g., gray, orange, calico, etc). These figures for kittens consisted of 1303 (14.4\%) black only, $1170(12.9 \%)$ primarily black with other colors, and 6598 (72.7\%) other colored cats. For cats over one year of age, $689(10.8 \%)$ were black only, $721(11.3 \%)$ were primarily black with other colors, and 4968 (77.9\%) were other colors. Cats with no identified coat color were eliminated from analysis.

\section{COAT COLOR AND ADOPTION TIME}

\section{DFL}

A difference in length of days required for adoption was found for cats of different coat colors $(F=11.17(p<.000)$. The average number of days until adoption for black cats was 26.25 (SD 24.27), black primarily with other colors was 23.40 (SD 22.00) and other colored cats was 24.01 (SD = 22.43). Pairwise comparisons (LSD least significant differences) found a significant difference between black only and both black primary (mean difference $=2.97$, std error, .725, $\mathrm{p}<.000$ ) and 'other' (mean difference $=2.43$, std error, .553, $\mathrm{p}<.000)$. The difference between black primary and 'other' was not significant. Although sex of the cat and length required for adoption was statistically significant $(\mathrm{F}=$ $14.01(\mathrm{p}<.000)$, there was no interaction between sex and coat color (Table $\mathbf{1})$.

\section{LHS}

Similar results were found for both adult and juvenile cats at LHS. A significant difference in adoption time for cats under one year of age was found based on coat color $(\mathrm{F}$ $=23.78, \mathrm{p}<.000)$. Black kittens required an average of 18.03 days $(\mathrm{SD}=19.51)$ to be adopted, compared to 15.86 (SD 19.44) days for primarily black and 13.99 ( $\mathrm{SD}=18.82$ ) for other colored kittens. Pairwise comparisons (LSD least significant differences) found a significant difference between black only and both primarily black (mean difference $=1.85$, std error, .773, p<.017) and other color (mean difference $=3.80$, std error, .583, p<.000). The difference between primarily black and other coat color was also significant (mean difference $=1.96$, std error, .606, $\mathrm{p}<.001)$. The difference between male and female altered kittens was not statistically significant.

The adoption patterns of adult cats demonstrated similar trends. Coat color was found to be a significant variable on adoption time $(\mathrm{F}=25.21 \quad(\mathrm{p}<.000)$. Cats with black only coats averaged 26.55 ( $\mathrm{SD}=25.09$ ) days to adoption, those with black as a primary coat color averaged 23.75 (SD 29.33) days and other colored cats averaged 20.64 (SD 21.02) days. Pairwise comparisons (LSD least significant differences) found a significant difference between black only and both primarily black (mean difference $=2.77$, std error, $1.20, \mathrm{p}<.021$ ) and other (mean difference $=5.99$, std error, .918, $\mathrm{p}<.000)$. Additionally, the difference between primary black and other coat color was significant (mean difference $=3.22$, std error, $.900, \mathrm{p}<.001$ ). Although there was a difference in length of time to adoption based on sex (3.79, $\mathrm{p}<.052)$, there was not a significant interaction between sex and coat color (Tables $\mathbf{2}$ and $\mathbf{3}$ ).

\section{DISCUSSION AND CONCLUSION}

Results of this study suggest that the color of a cat's coat influences the time required for adoption. Black cats require the longest time to adopt, followed by those that have primarily black coats with other colors mixed in, and then all other colored cats. Data from LHS indicated a statistically significant difference between all three color groups, while data from DFL followed a similar trend (longest adoption time for black cats, followed by primary black and other

Table 1. DFL Days Until Adoption for Neutered and Spayed Kittens Under One Year of Age

\begin{tabular}{|l|c|c|c|c|c|c|}
\hline \multirow{2}{*}{} & \multicolumn{2}{|c|}{ Neutered } & \multicolumn{2}{c|}{ Spayed } & \multicolumn{2}{c|}{ Total } \\
\cline { 2 - 7 } & Mean & SD & Mean & Mean & SD \\
\hline \hline Black only (n=2062) & 25.08 & 24.12 & 27.79 & 24.39 & 26.25 & 24.27 \\
\hline Primarily black with other color(s) (n=1910) & 23.04 & 21.37 & 23.89 & 22.81 & 23.40 & 22.00 \\
\hline Other color(s) (n=9666) & 22.94 & 21.90 & 25.07 & 22.90 & 24.01 & 22.43 \\
\hline
\end{tabular}

Coat color: $F=11.17(\mathrm{p}<.000)$.

Sex: $\mathrm{F}=14.01(\mathrm{p}<.000)$.

Table 2. LHS Days Until Adoption for Neutered and Spayed Cats Over One Year of Age

\begin{tabular}{|c|c|c|c|c|c|c|}
\hline & \multicolumn{2}{|c|}{ Neutered } & \multicolumn{2}{|c|}{ Spayed } & \multicolumn{2}{|c|}{ Total } \\
\hline & Mean & SD & Mean & SD & Mean & SD \\
\hline Black only $(n=689)$ & 25.93 & 25.81 & 27.19 & 24.33 & 26.55 & 25.09 \\
\hline Primary black with other color(s) $(n=721)$ & 22.90 & 28.70 & 24.68 & 30.05 & 23.75 & 29.33 \\
\hline Other color(s) $(n=4968)$ & 19.66 & 21.01 & 21.47 & 21.00 & 20.64 & 21.02 \\
\hline
\end{tabular}

Coat color: $\mathrm{F}=25.21(\mathrm{p}<.000)$.

Sex: $F=3.79(\mathrm{p}<.052)$. 
Table 3. LHS Days Until Adoption for Neutered and Spayed Kittens Under One Year of Age

\begin{tabular}{|c|c|c|c|c|c|c|}
\hline & \multicolumn{2}{|c|}{ Neutered } & \multicolumn{2}{|c|}{ Spayed } & \multicolumn{2}{|c|}{ Total } \\
\hline Primary black with other color(s) $(n=1170)$ & 15.23 & 18.11 & 16.67 & 20.10 & 15.86 & 19.44 \\
\hline Other color(s) $(n=6598)$ & 14.04 & 18.13 & 13.94 & 19.47 & 13.99 & 18.82 \\
\hline
\end{tabular}

colors), but the difference between primary black cats and those of other colors was not statistically significant. After conferring with shelter staff, it was felt this was likely due to differences in coat color coding. Differentiating between 'primary black' and 'other colors' for many of the cats was felt to be subjective with the amount of black needed to be considered 'primary' open to interpretation. It is suggested that one possible explanation for the fact that the differences in adoption time for black cats and cats of other colors was statistically significant at LHS, but not at DFL, may have been due to DFL staff feeling that a greater percentage of black in cats' coat color was necessary to obtain the 'primary black' coding as compared to LHS. In future studies, it is suggested that actual pictures be used for coding by researchers as one way to create additional consistency in color coding. Additionally, this method could be used to accurately code other coat colors in future analyses.

The common perception of shelter workers who report the negative impact of black coat color on adoption rate is supported by these results. Commonly referred to as "black dog syndrome", the difficulty faced by black animals in terms of adoption has long been accepted by shelter workers [20]. With mostly anecdotal information, there has been little actual research to support this theory [21]. Our study attempts to fill this void. Our results suggest that it requires approximately three more days for adult black cats to be adopted than cats with black as a primary coat color (e.g. tuxedo) cats, and two to six more days than cats of other colors. Interestingly, this trend remains consistent, regardless of whether the cat is an adult or juvenile. Although as a group, kittens are adopted more quickly than adult cats, there is still a two to three day difference between black kittens and kittens that are primarily black with other colors, and a two to four day delay when compared to kittens of other colors.

The fate of shelter cats is ultimately that of reclamation, adoption, or euthanasia [22]. Understanding the factors involved in adoption decisions is a critical aspect of the shelter world. Unfortunately, housing cats in shelters is a necessary component of animal management but comes with significant costs. Given the inherently stressful environment of a shelter and the impact of stress on cats' health, attempting to keep cats healthy while sheltered can be extremely difficult. It is not surprising that shelters are especially prone to outbreaks of infectious diseases. Sick cats are a major hardship for shelters, draining financial resources and commonly leading to difficult euthanasia decisions [9]. Even as veterinary medicine and the shelter community struggle to optimize the health of shelter animals and minimize the risk of infectious diseases, they do so with the inherent limitations of inadequate funds [23].

Given these challenges, it is important to note that just a few additional days at a shelter carries serious ramifications for the health and ultimate fate of a sheltered cat. As several studies have indicated, the likelihood that a cat will contract an infection is significantly impacted by their length of time in a shelter [7-9, 11, 14]. In other words, days matter. Given that black cats appear to be at a disadvantage for adoption, it places them at a higher risk for sickness and as a result, euthanasia. It is suggested, therefore, that shelters might want to explore options to decrease the length of stay prior to adoption for their black cats.

With an increasing number of adopters searching online for adoptable pets, it is possible that creating better photographs of black cats might be helpful. Black animals are notoriously harder to photograph, but improvements including brightly colored collars or ribbons, or adjustments in lighting and shutter speed might be helpful. Other suggestions include photographing black cats in a safe area indoors with lots of windows [24].

In addition to photogenic properties, black cats continue to be plagued by a negative association with superstition, specifically - magic and witches. In fact, a common Halloween image is that of a black cat with a witch [25, 26]. This connection with magic and witches may lead some people to select cats of other colors. To help mitigate the negative ramifications of poor photogenic properties and an association with superstition, it is suggested that shelter staff pay more attention to the naming of black cats, refraining from 'classic' black animal names (e.g., Blackie, Gypsy, Midnight, etc). It is possible that 'cute' or 'human' names might help black cats. Additionally, placing black cats at the top of adoption lists or on the front pages of websites could increase exposure. Shelters might also want to consider creating special 'black cat' events. Examples include black cat adoption days (e.g., reduced rates for black cats) or special events focused around black cats (i.e., black tie affairs, etc.). The use of light colored bedding and/or toys inside cages might also enhance the visibility and appeal of black cats.

With data to support the premise that black cats take longer to adopt, shelters can perhaps justify allocating resources towards making positive changes in this area. In follow up studies, it will be important to assess the impact of any of these interventions to determine effectiveness. 
Limitations of the present study include the fact that data were collected from only two animal shelters with average adoption rates higher than the national average. While we expect the observed trends to generalize to other shelters, the actual time differences in length of stay may vary. Because the study was conducted within Colorado, care must be taken when extrapolating results to other areas of the country. The shelters in this study, however, employ animal housing and management conditions similar to numerous other shelters in the US. Despite these limitations, the present findings appear to provide important information on the impact coat color has on the adoption time for adult and juvenile cats.

\section{ABBREVIATIONS}

$\begin{array}{lll}\text { DFL } & = & \text { Dumb Friends League } \\ \text { LHS } & = & \text { Larimer Humane Society } \\ \text { URI } & = & \text { Urinary tract infection } \\ \text { URTD } & & \text { Upper respiratory tract infection }\end{array}$

\section{CONFLICT OF INTEREST}

The authors confirm that this article content has no conflict of interest.

\section{ACKNOWLEDGEMENTS}

The authors wish to thank the staff at Larimer Humane Society and Dumb Friends League for their assistance in obtaining data for this study.

\section{REFERENCES}

[1] The Humane Society of the United States website. Common questions about animal shelters. Available at: www.humanesociety. org/animal_community/resources/qa/common_questions_on_shelte rs.html\#How_many_animals_enter_animal_shelters_e [Accessed: March 29, 2012].

[2] American Humane Association website. Animal shelter euthanasia. Available at: www.americanhumane.org/animals/stop-animal-abus e/fact-sheets/animal-shelter-euthanasia.html [Accessed: March 29, 2012].

[3] Griffin J. Stress and immunity: a unifying concept. Vet Immunol Immunopathol 1989; 20: 263-312.

[4] Bannasch MJ, Foley JE. Epidemiologic evaluation of multiple respiratory pathogens in cats in animal shelters. J Feline Med Surg 2005; 7: 109-19.

[5] Steneroden, KK, Hill AE, Salman, MD. A needs-assessment and demographic survey of infection-control and disease awareness in western US animal shelters. Prev Vet Med 2011; 98: 52-7.

[6] Lord LK, Reider L, Herron ME. Health and behavior problems in dogs and cats one week and one month after adoption from animal shelters. J Am Vet Med Assoc 2008; 233: 1715-22.

[7] Dinnage JD, Scarlett JM, Richards JR. Descriptive epidemiology of feline upper respiratory tract disease in an animal shelter. J Feline Med Surg 2009; 11: 816-25.
[8] Edinboro CH, Janowitz LK, Yoran-Guptill L, et al. A clinical trial of intranasal and subcutaneous vaccines to prevent upper respiratory infection in cats at an animal shelter. Feline Pract 1999; 27: 7-13.

[9] Pedersen NC, Sato R, Foley J, et al. Common virus infections in cats, before and after being placed in shelters, with emphasis on feline enteric coronavirus. J Feline Med Surg 2004; 6: 83-8.

[10] Tanaka A, Wagner DC, Kass PH, et al. Associations among weight loss, stress, and upper respiratory tract infection in shelter cats. J Am Vet Med Assoc 2012; 240: 570-6.

[11] Gaskell RM, Povey RC. Experimental induction of feline viral rhinotracheitis virus re-excretion in FVR-recovered cats. Vet Rec 1977; 100: 128-33.

[12] Gourkow N, Fraser D. The effect of housing and handling practices on the welfare, behavior and selection of domestic cats (Felis sylvestris catus) by adopters in an animal shelter. Anim Welf 2006; 15: 371-7.

[13] Podberscek AL, Blackshaw JK. Reasons for liking and choosing a cat as a pet. Aust Vet J 1988; 65: 332-3.

[14] Fantuzzi JM, Miller KA, Weiss E. Factors relevant to adoption of cats in an animal shelter. J Appl Anim Welf Sci 2010; 13: 174-9.

[15] Lepper M, Kass PH, Hart LA. Prediction of Adoption Versus Euthanasia Among Dogs and Cats in a California Animal Shelter. J Appl Anim Welf Sci 2002; 5: 29-42.

[16] Wells D, Hepper PG. Behaviour of kenneled dogs. Anim Welf 1992; 1: 171-86.

[17] Larimer Humane Society website. Available at: www.larimerhumane.org [Accessed: March 30, 2012].

[18] U.S. Census Bureau website. State and County QuickFacts. Available at: quickfacts.census.gov/qfd/states/08/08069.html [Accessed: March 30, 2012].

[19] Dumb Friends League website. Exhibit A - Animal Statistics Table: Traditional Shelter. Available at: www.ddfl.org/sites/default/files/A silomarstats-2010.pdf [Accessed March 30, 2012].

[20] Time website. Are Black Pets Less Likely to Be Adopted? Available at: newsfeed.time.com/2011/10/12/are-black-pets-less-likelyto-be-adopted/ [Accessed: March 30, 2012].

[21] USA Today website. Black dog syndrome bad luck for rescue shelters. Available at: yourlife.usatoday.com/parenting-family/pets/ story/2011-10-04/Black-Dog-Syndrome-bad-luck-for-rescue-shelte rs/50661204/1 [Accessed March 30, 2012].

[22] Dantas-Divers LMS, Crowell-Davis SL, Alford K, et al. Agonistic behavior and environmental enrichment of cats communally housed in a shelter. J Am Vet Med Assoc 2011; 239: 796-802.

[23] Petersen CA, Dvorak G, Steneroden K, Spickler AR. Introduction to Infection Control for Animal Shelters. In: Petersen CA. Dvorak G, Spickler AR, Eds. Maddie's Infection Control Manual for Animal Shelters. Center for Food Security and Public Health. Ames, Iowa: Iowa State University 2008; pp. 2-16.

[24] Second Chance Photos website. Photo shoot tips. Available at secondchancephotos.org/index2.php\#/info2/3/ [Accessed: March 30, 2012].

[25] Mills JE. Witches in America: America's Supernatural Secrets. New York, New York: Rosen Publishing Group 2011.

[26] Allred AP. Cats' Most Wanted: The Top 10 Book of Mysterious Mousers, Talented Tabbies, and Feline Oddities. Dulles, VA: Potomac Books Inc; 2005. 